\title{
CHINA: SOCIALISMO DE MERCADO, RELAÇÕES INTERNACIONAIS E QUESTÃO IDEOLÓGICA
}

Marcos Aurélio da Silva ${ }^{1}$

Resumo. Definindo as características do socialismo de mercado chinês, bem como os efeitos que esta formação social imprime às suas relações internacionais, o artigo discute as leituras ideológicas que esta realidade tem recebido nos meios intelectuais e políticos ocidentais nas últimas décadas e durante a atual pandemia da Covid-19. O pano de fundo teórico desta análise parte da noção de unidade e racionalidade da história inerente a um marxismo que se reconhece escoltado pela filosofia clássica alemã e notadamente pelo pensamento de Hegel.

Palavras-chave: China. Socialismo de mercado. Relações internacionais. HegelMarx.

\section{CHINA: MARKET SOCIALISM, INTERNATIONAL RELATIONS AND IDEOLOGICAL ISSUE}

Abstract. Defining the characteristics of Chinese market socialism, as well as the effects that this social formation has on its international relations, the article discusses the ideological readings that this reality has received in the western intellectual and political circles in the last decades and during the current pandemic of Covid -19. The theoretical background of this analysis starts from the notion of unity and rationality of history inherent to a Marxism supported on classic German philosophy and notably on Hegel's thinking.

Keywords: China. Market socialism. International relations. Hegel-Marx.

\section{CHINA: SOCIALISMO DE MERCADO, RELACIONES INTERNACIONALES $Y$ CUESTIÓN IDEOLÓGICA}

Resumen. Definiendo las características del socialismo de mercado chino, así como los efectos que esta formación social tiene en sus relaciones internacionales, el artículo analiza las lecturas ideológicas que esta realidad ha recibido en los círculos intelectuales y políticos occidentales en las últimas décadas y durante la actual pandemia de Covid-19. El trasfondo teórico de este análisis parte de la noción de unidad y racionalidad de la historia inherente a un marxismo respaldado por la filosofía clásica alemana y especialmente por el pensamiento de Hegel.

Palabras clave: China. Socialismo de mercado. Relaciones internacionales. HegelMarx.

\section{Introdução: o avesso do pós-modernismo}

\begin{abstract}
Para avançar em direção ao novo, ao jovem, ao possível, ocorre tornar-se consciente da natureza dos condicionamentos que ficaram para trás, dos 'grilhões do mundo', olhar de frente a 'absoluta devastação', percorrer novamente as etapas do longo caminho atravessado, fixando-se em cada uma delas. Isso é necessário para nos tornarmos contemporâneos de nós mesmos, para poder contemplar a figura do novo mundo que surge no 'saber absoluto', absolutus, saído de cada condicionamento, liberado daqueles 'grilhões' do passado que ainda aprisionam os homens nas representações, nos conceitos e nos comportamentos éticos, intimamente
\end{abstract}

\footnotetext{
${ }_{1}^{1}$ Universidade Federal de Santa Catarina, Departamento de Geociências, Florianópolis, Brasil, maurelio@cfh.ufsc.br, https://orcid.org/0000-0002-2228-9664.
} 
enfraquecidos, eclipsados, mas ainda em condições de exercer um residual impulso inercial.

(Da introdução de Remo Bodei à 'Vita di Hegel', de Karl Rosenkranz)

Se há um tema a partir do qual deveríamos pautar qualquer discussão sobre a China hoje, este certamente é o da ideia da unidade e da racionalidade da história cara ao pensamento marxista que se reconhece herdeiro de Hegel. Podemos tomar como critério de avaliação deste argumento a primeira parte do livro de Xi Jinping recentemente lançado no Brasil (JINPING, 2019).

De fato, já no primeiro artigo desta obra, extrato de um discurso de Xi na entrevista que concedeu a jornalistas chineses e estrangeiros por ocasião do $18^{\circ}$ Congresso Nacional do Comitê Central do Partido Comunista Chinês (PCCh) - o mesmo que o elegeu secretário-geral -, a ideia a qual nos referimos aparece muito claramente. Fala-se de "tomar o bastão dessa corrida de revezamento passada pela história", ou ainda na necessidade de "trabalhar pelos interesses públicos e atuar com diligência em um esforço para cumprir as expectativas da história e do povo" (JINPING, 2019, pp. 4-5). Do mesmo modo, nas passagens sobre as exigências de construção do partido decididas no $18^{\circ}$ Congresso, emergem com centralidade, e sem que isto signifique ignorar as "mudanças das situações interna e externa", a noção de herança e, logo, de sentido da história. É quando o texto se refere às "missões históricas assumidas", destacando a necessidade de "herdar e desenvolver a natureza avançada que o nosso partido, um partido político marxista, tem mantido e desenvolvido ao longo de mais de 90 anos" (JINPING, 2019, p. 17).

É um tema que retorna igualmente nas referências de $\mathrm{Xi}$ às teorias do marxismo, lembradas por ocasião de um discurso que trata do pensamento de Mao Zedong. "As teoria do marxismo são verdades universais de valores permanentes", recorda a liderança chinesa, que ainda no mesmo discurso, tratando da "linha de massas" - "fazer com que o povo julgue nossos trabalhos" -, a elas se refere como "uma lei férrea do desenvolvimento histórico que serve a todos os partidos, sem nenhuma exceção, quer seja no passado ou no presente, quer seja na China ou no exterior" (JINPING, 2019, pp. 32-34). Ou ainda quando, discorrendo sobre os meios para "enriquecer" o "sistema teórico do nosso socialismo", insiste na necessidade de "aprender e assimilar respeitosa e sinceramente todos os frutos das civilizações criados pela sociedade humana", desde que isso não signifique "ignorar a nossa própria história, nem copiar e imitar os modelos de desenvolvimento alheios, nem aceitar qualquer pregação arrogante dos outros" (JINPING, 2019, p. 36). 
Não é de surpreender que justamente a primeira parte da obra, que nos serviu para as citações acima, seja dedicada a definir o "socialismo com características chinesas", pensado, sim, à luz de muitas inovações, mas sem que isto signifique abdicar da própria história e da teoria que anima a sua compreensão. Com efeito, é na parte 4, destinada a apresentar o "aprofundamento da reforma", que se vê descortinar as referências de Xi Jinping ao conhecido Prefácio de Marx à Contribuição à Crítica da economia Política (MARX, 1983), obra de referência para marxistas de diversas gerações em diferentes lugares do mundo. No texto de Xi Jinping, clara expressão da política de reformas, lê-se:

A base econômica determina a superestrutura. A política de reformas tem uma influência importante e generalizada sobre as reformas em outros setores. $O$ progresso das importantes reformas na estrutura econômica determina 0 processo de reformas de muitos outros domínios, desempenhando um papel crítico na situação geral (JINPING, 2019, p. 116).

Não há dúvida, a ideia de unidade e fundamento da história é central para compreender a China de nossos dias. Mais que isto, é uma ideia que, na esteira da gramática que Marx sustenta no Prefacio, não se envergonha de articular mudança histórica e tendências de fundo do processo histórico. São os elementos daquela relação entre o "real e o racional" que em Hegel remete à "realidade em sentido forte" (Wirklichkeit), não identificada com a simples empiria, mas tão-pouco tomando esta última como um simples "nada" (HEGEL, 2009, p. 9, LOSURDO, 2011, pp. 91 e segs.)². Trata-se já do exato oposto do ideário hoje dominante no mundo da cultura ocidental, associado à pós-modernidade. De fato, para a démarche pós-moderna, falar de um "fundamento da história" é um postulado completamente "obsoleto", o que equivale derrubar a própria ideia de "história e sociabilidade como totalidade inteligível", "constituída em torno de leis explicáveis conceitualmente" - ou seja, a ideia de história como totalidade transparente, penetrável, inervada por uma lógica imanente (verbi gratia, a lógica da luta de classes), própria das formas mais evoluídas da razão humana, como o disse recentemente o filósofo Stefano Azzarà, demarcando a diferença entre a tradição hegeliano-marxista e a razão populista, a mesma razão que, ponto de chegada da forma mentis pós-moderna, domina hoje, à esquerda e à direita, o mundo do dissenso (AZZARÀ, 2017, pp. 28 e segs.).

\footnotetext{
2 "Já uma consideração inteligente do mundo distingue isso que do vasto reino da existência interna e externa é simples aparição, fugaz e insignificante, e isso que em si merece verdadeiramente o nome de realidade" (HEGEL, 2009, p. 9). Na mesma página, a nota da edição aqui consultada acrescenta: "Wirklichkeit', efetividade; que Hegel às vezes distingue da 'Realität".
} 


\section{O "socialismo com características chinesas"}

... os mestres do socialismo não falavam gratuitamente de todo um período de transição do capitalismo para o socialismo e não sublinhavam em vão as 'longas dores de parto' da nova sociedade, e, além disso, esta nova sociedade é também uma abstração, que só pode encarnar na vida através de uma série de tentativas concretas, imperfeitas e variadas, para criar este ou aquele Estado socialista.

(V. I. Lénine, Acerca do infantilismo de esquerda e do espírito pequeno burguês)

Até mesmo em razão da "linha de massas", é muito comum nos textos oficiais do PCCh a expressão "povo", a ideia de que "o povo é o criador da história", a ideia do "poder concedido pelo povo" (JINPING, 2019, pp. 32-33). Mas uma vez posta a noção de história como "totalidade inteligível", é inadmissível pensar que a construção do socialismo na China pudesse fazer qualquer concessão ao "mito populista" segundo o qual "a consciência revolucionária, a perspectiva de uma sociedade mais justa, seria o dado natural e imediato do povo, dos humildes, dos oprimidos" - vale dizer, que pudesse renunciar à "análise laica das classes e da luta de classe para substituí-la com a crença mitológica no valor salvífico do 'povo' e das 'massas'”, categorias que, já distantes da gramática e da sintaxe de Marx, a toda prova se inclinam a uma "concepção da história como conspiração" (LOSURDO, 2019, pp. 88 e 91).

Compreende-se assim que os elementos do que hoje é chamado "socialismo com características chinesas", lançados em 1982 por Deng Xiaoping e fundados na ideia de reforma e abertura, mais que uma hipotética traição, como gostaria uma versão qualquer da "história como conspiração", correspondem a formulações em torno das estruturas da história elaboradas ainda antes da Revolução de 1949. Já em 1940, Mao Zedong anotava que, por seu "caráter social, na primeira fase ou no primeiro passo, a revolução de uma colônia ou semi-colônia permanece fundamentalmente uma revolução democrático-burguesa, e objetivamente sua meta é deixar o terreno livre para o desenvolvimento do capitalismo" (LOSURDO, 2004, p. 144). No caso particular da China, "para levar a economia a um nível mais alto", dever-se-ia "utilizar todos os fatores do capitalismo urbano e rural que são vantajosos e não nocivos à economia nacional e à vida do povo'", devendo mesmo os comunistas "unir-se "à burguesia nacional em uma luta comum" (BERTOZZI, 2015, p. 49). E já à frente do Estado nacional, em 1957, Mao é ainda uma vez explícito ao lançar a palavra de ordem de um "esforço coletivo que não exclui a 
colaboração com uma burguesia sinceramente nacional", fazendo notar que a "contradição entre a burguesia nacional e a classe operária", e mais geralmente aquela "entre explorados e exploradores", embora tenha um "caráter antagonístico, nas condições concretas da China... pode ser transformada, se tratada de modo justo, 'em contradição não antagonista e ser resolvida com métodos pacíficos'" (BERTOZZI, 2015, p. 49).

São os princípios que irão nortear a política de reformas de Deng Xiaoping, decidida sob a pressão do enorme fracasso da Revolução Cultural (e do Grande Salto para Frente que a precedeu), com os "pequenos altos-fornos de vilarejo instalados sob a onda do entusiasmo de massa", numa espécie de "militarização da economia" baseada em "um forte sentido comunitário" e "um radical igualitarismo" que lembra a "Rússia soviética durante a fase do "comunismo de guerra'” (LOSURDO, 2004, p. 149). Desafiado a enfrentar uma assoladora realidade, marcada por cerca de 10 a 30 milhões de trabalhadores sem ocupação no setor urbano, outros 40 a 90 milhões no setor agrícola, 100 milhões de chineses mal nutridos e um exército tecnologicamente atrasado (BERTOZZI, 2015, p. 50), Deng Xiaoping, no ano de 1985, irá declarar:

\begin{abstract}
Nós devemos aprender com os povos dos países capitalistas. Devemos fazer uso da ciência e da tecnologia que eles desenvolveram, e dos seus conhecimentos e experiência acumulada que podem ser adaptados ao nosso uso. Uma vez que iremos importar tecnologia avançada e outras coisas para nós úteis dos Países capitalistas - de modo seletivo e planificado - não iremos nunca aprender nem importaremos o sistema capitalista (XIAOPING Apud BERTOZZI, 2015, p. 50).
\end{abstract}

Conhecemos a forma como o processo foi posto em marcha. Uma modernização "onda após onda", voltada a "concentrar antes de tudo os esforços reformadores em algumas regiões, empresas e trabalhadores para elevar-lhes o teor de vida, fornecendo um exemplo para toda a economia nacional" (BERTOZZI, 2015, p. 50), que iniciou por províncias ao sul e pela costa leste, em regiões vizinhas do Japão, aos chamados Tigres Asiáticos, e demais economias capitalistas da região, dando lugar a uma "fusão do Estado desenvolvimentista com o Estado revolucionário" (OLIVEIRA, 2006, p. 35):

Pensemos nas Zonas econômicas especiais (ZES) lançadas a partir de 1979 em áreas da costa oriental e meridional (Zhuhai próximo a Macao, Xiamen em frente a Taiwan, Shantou e Shezhen junto a Hong Kong) com o escopo de atrair investimentos e tecnologia estrangeira, garantindo isenção fiscal de até $50 \%$ e eliminação de taxas de importação de materiais e equipamentos de importação. Na região de Sichuan o experimento prevê a entrega em arrendamento das terras das comunas a famílias individuais de camponeses que poderiam vender a colheita ao Estado a preços por ele estabelecidos. Sucessivamente, à luz dos resultados positivos dos experimentos, é estendida a duração dos períodos de arrendamento e 
concedida a liberdade para vender grande parte da colheita nos mercados livres instituídos nas cidades e para dar vida a atividades econômicas colaterais (BERTOZZI, 2015, p. 50).

Retomemos a discussão que abriu esta seção. Este processo, muito distante de qualquer forma de traição, em tudo lembra a NEP de Lenin, não por acaso "explicitamente citada" por Deng Xiaping (LOSURDO, 2013, p. 317). A rigor, um "acordo entre o proletariado, que exerce a sua ditadura ou detém nas suas mãos o poder do Estado, e a maioria da população camponesa", o que significa pôr "mercadorias em circulação" para reanimar a "pequena agricultura", pois "é possível" "restaurar até certo ponto a liberdade de comércio, a liberdade do capitalismo para os pequenos agricultores, sem minar com isto as raízes do poder político do proletariado", mesmo que isso signifique "estimular os kulaques", contra os quais não se deve lutar "com proibições, mas com a organização do Estado e com medidas estatais de cima" (LÉNINE,1982, pp. 475-482).

Obviamente o processo chinês "se apresenta como uma espécie de gigantesca e prolongada NEP" (LOSURDO, 2004, p. 67). E ainda assim é patente a completa inadequação, já a partir dos clássicos mesmo do marxismo, da oposição entre "socialismo" e "mercado". Trata-se, se nos é permitida uma incursão em torno das reflexões de Gramsci a este respeito, de uma ideia de mercado distante de qualquer "sentido naturalístico", uma ideia rigorosamente "historicista", que "se verifica" em um "ambiente organicamente vivo e conexo em seus movimentos de desenvolvimento", numa palavra, uma "forma social determinada, do todo em confronto com a parte", de "toda uma série de atividades humanas, que podem ser chamadas 'econômicas' só alargando e generalizando enormemente a noção de economia" (GRAMSCI, 1975, pp. 1247-8 e 1269). O mesmo Gramsci, cabe notar, que sustenta o programa da NEP para os comunistas italianos desde pelo menos 1926, quando elabora, ainda no período pré-carcerário, o famoso Alcuni temi della quistione meridionale (GRAMSCI, 1967, pp. 720-742), e que continua a fazê-lo até seus últimos escritos no cárcere mussoliniano (GRAMSCI, 1975, pp. 2025 e segs.). Não sem antes, deve-se dizer, ter debatido o problema com o próprio Lenin, com quem, versando sobre a questão das alianças com os socialistas e sobre o Mezzogiorno, teve dois dedos de prosa na noite de 25 de outubro de 1922, quando em Moscou para o IV Congresso da Internacional Comunista (D'ORSI, 2018, p. 190).

Com efeito, a discussão acima não é gratuita e sem qualquer vínculo com o que agora observamos na experiência chinesa. Afinal, é pouco observado que 
Gramsci, embora um persistente teórico da NEP, fórmula mesmo a partir da qual desenvolve toda uma contribuição para a teoria do Estado através do conceito de hegemonia, chegou a se referir de maneira positiva, em uma carta a mulher Giulia de 31 de junho de 1931, à piatilietica soviética (GRAMSCI, 1996, p. 424) - vale dizer, aos planos quinquenais iniciados por Stalin e que vieram substituir a NEP leniniana - e a rigor derrubar a aliança operário-camponesa. Teria sido uma reflexão desta natureza, de "superior fineza e maturidade", isto é, capaz "de compreender as dificuldades e as razões da sociedade e da história" que operam estas mudanças, inclusive com seus problemas teóricos (LOSURDO, 2016, p. 31), a mesma que levaram a efeito, e por conta própria, os comunistas chineses a partir de 1978, a ponto de combinar originalmente Plano Quinquenal e NEP?

Não parece ser outro senão este o sentido de que ao mercado, no socialismo, pode ser confiado "um papel regulador auxiliar sob orientação da economia planificada" (BERTOZZI, 2015, p. 50) - uma economia apoiada nos "próprios esforços como recurso principal" e que procura "ajuda exterior como recurso auxiliar, política elaborada a seu tempo pelo Presidente Mao", insiste o dirigente que lança as bases materiais do "socialismo de mercado" (XIAOPING, 1984, p. 377). Eis uma realidade que parece se confirmar ainda mais com as mais recentes direções, convidando as reflexões em torno do socialismo de mercado a destacar o papel crescente do plano no interior desta forma compósita. Se Jiang Zemin, o formulador do conceito de socialismo de mercado ${ }^{3}$, propunha que "mercado e plano" deveriam ser "instrumentos julgados de igual dignidade para a regulação da economia", evitando distinguir "plano e mercado" em "dois sistemas", reflexões como a do geógrafo e economista Elias Jabbour, partindo do conceito de "economia do projetamento" de Ignácio Rangel, propõem que o "projeto" e não o "mercado" passa a ser cada vez mais o "ente abstrato" central do planejamento socialista chinês, "fruto de uma maxiracionalização do processo de produção, causa e conseqüência do surgimento de novas e superiores formas de planificação econômica" (JABBOUR, 2020). E, no entanto, justamente por esta centralidade dada ao projeto, a planificação agora se abre para a solução de problemas que, sem abandonar a centralidade da economia, estão além da própria produção ou, mais rigorosamente, se "libertam" da economia por meio de uma superação dialética

\footnotetext{
${ }^{3}$ Se Deng Xiaoping (1978-1992) é o responsável por lançar as quatro modernizações - ciência, indústria, agricultura e forças armadas, mas atribuindo à primeira "o papel de base das outras três" (OLIVEIRA, 2006, p. 34) -, é de Jiang Zemin (1993-2003) o conceito de "economia socialista de mercado", adotado no 14 Congresso do PCCh, em 1992 (BERTOZZI, 2015, p. 57).
} 
(Aufhebung) - a superação de um "conteúdo determinado" da economia, mas não da economia enquanto tal -, no exemplo da construção de um Welfare e de uma ecocivilização. É o que Xi Jinping, enfatizando a "fase inicial do socialismo" em que se encontra ainda a China, chama de "planejamento global", "forma superior" de planificação que encontra sua realização prática no desenvolvimento "cinco em um":

Foi salientado no $18^{\circ}$ Congresso Nacional do Partido que o fundamento básico para a construção do nosso socialismo é que a China está na fase inicial do socialismo, o planejamento global visa promover 0 desenvolvimento 'cinco em um' e a tarefa geral é alcançar a modernização socialista e a grande revitalização nacional. (...) Devemos ter essa realidade em mente sob quaisquer circunstâncias e promover a reforma e o desenvolvimento integrais com base nesta realidade. Devemos nos basear nesta realidade não apenas na construção econômica, mas também na promoção do desenvolvimento político, cultural, social e da ecocivilização; não apenas quando o nosso volume total da economia for pequeno, mas também quando o volume econômico aumentar; não apenas ao planejarmos o desenvolvimento de longo prazo, mas também ao trabalharmos no cotidiano (JINPING, 2019, p. 12).

Estamos diante de uma teorização que dá sentido ulterior às formulações e mudanças levadas a efeito pela geração imediatamente precedente a de Xi Jinping, ligada ao nome de Hu Jintao (2003-2013). É esta geração que, diante de problemas ligados ao "aumento das disparidades de renda, mesmo ao nível regional", e da "poluição e insustentabilidade ambiental", dá início à "tarefa de promover uma virada em relação a um desenvolvimento considerado pouco racional e medido apenas em termos de PIB", o que leva à "constitucionalização do conceito de "visão científica do desenvolvimento', a verdadeira contribuição teórica de Hu Jintao ao socialismo com características chinesas" (BERTOZZI, 2015, pp. 60-61). E os resultados são já palpáveis. O greenreport.it, diário dedicado à economia ecológica do jornal italiano La Repubblica, noticiou em fevereiro de 2019 que um estudo da NASA concluiu ter a Terra se tornado mais verde nos últimos 20 anos como resultado dos "ambiciosos programas de plantio de árvores da China e da agricultura intensiva" da Índia e da China, sendo que "a extraordinária contribuição da China a esta tendência global ao 'greening' alcança cerca de $42 \%$ dos programas de conservação e expansão das florestas", desenvolvidos "na tentativa de reduzir os efeitos da erosão do solo, da poluição atmosférica e das mudanças climáticas" (GREENREPORT.IT, 13.02. 2019) ${ }^{4}$. No plano da contribuição para a reconversão industrial em direção a uma economia verde, é notável o fato de que em 2017 "um quinto de todos os carros elétricos do mundo foi vendido em apenas seis cidades

\footnotetext{
${ }^{4}$ A notícia ainda acrescenta: "os reflorestamentos dos pioneiros chineses não são só propaganda do regime: funcionam". Veja-se http://www.greenreport.it/news/agricoltura/il-mondo-e-diventato-piuverde-grazie-a-cina-e-india/ (Acesso em 21.02.2019).
} 
chinesas onde já existe legislação restringindo a utilização de carros movidos por combustíveis fósseis" (JABBOUR, 2020, p. 23), bem como de que a China é "líder global" em "tecnologia de energia limpa (eólica e solar)" (BARELLA, 2020, p. 8). Do lado da organização de um Welfare chinês, é lançado em 2003 um "sistema de segurança à saúde rural" que em 2011 se transforma em um sistema "sanitário urbano e rural que cobre $90 \%$ da população", ao passo que se decidiu "estender e generalizar em 10 anos um sistema de seguridade à velhice para todos os cidadãos com ou sem emprego fixo", entre outras determinações (BERTOZZI, 2015, p. 61).

$\mathrm{E}$ eis que a "desmessianização do projeto comunista" chinês (LOSURDO, 2004, p. 120) começa a pôr à prova as críticas que pensavam ser impossível o "socialismo de mercado" - dito uma "contradição de termos" - controlar as "devastações do mercado" pela "regulação do Estado e pela melhoria dos direitos sociais" (WOOD, 2001, p. 128).

Antes de finalizar esta seção, cabem algumas palavras a mais acerca da relação entre "mercado" e "planificação", notadamente no que diz respeito às suas relações com a forma política do Estado. Na medida em que teoriza o "socialismo de mercado", Jiang Zemin também estabelece a "teoria das três representações", que leva à mudança do PCCh de "partido da vanguarda do proletariado" para um partido aberto a outros setores da sociedade disponíveis a "aceitar o seu estatuto", o seu "programa" e "uma ação com ele coordenada", implicando mesmo na aceitação de "empreendedores privados" "no interior do partido" (BERTOZZI, 2015, p. 58). Nada leva a pensar, todavia, que a gramática de Marx esteja sendo rejeitada. As contradições de classe não são eliminadas, como o prova o fato de que "operários, camponeses e intelectuais" continuam a ser definidos como "a espinha dorsal" do partido, mas retidas como "contradições não antagônicas", segundo o dissera já Mao Zedong (BERTOZZI, 2015, p. 58), insistindo que os representantes da "burguesia nacional" podem ser considerados como "parte das grandes massas populares", “mas não constituem o seu corpo principal” (TSETUNG, 1979, p. 309-10).

Com efeito, as elaborações de Jiang Zemin, aprovadas no mesmo Congresso em que "é reafirmada com força a fidelidade aos princípios do marxismo-leninismo" (BERTOZZI, 2015, p. 57), fazem pensar, mutatis mutandis, naquele "compromisso" com os "capitalistas cultos" do qual falava Lenin já nos primeiros meses da Revolução (LÉNINE, 1981, p. 606). O mesmo Lenin que, assim como agora o faz Xi Jinping, já então naquele momento, pensava o processo revolucionário como um processo de longo prazo, realizado por "longas dores de parto" e por uma "série de 
tentativas concretas, imperfeitas" (LÉNINE, 1981, p. 603). E uma mesma perspectiva histórica encontramos em Gramsci, que nos Cadernos do Cárcere refere-se à Revolução Francesa como um processo transcorrido em "80 anos de convulsões por ondas sempre mais longas" (GRAMSCI, 1975, p. 1582).

\section{Reforma e relações internacionais: "zonas intermediárias", "teoria dos três mundos", "multipolaridade"}

Em uma referência de método para uma ciência geográfica que se deseja tributária do materialismo histórico, Milton Santos, recorrendo não por acaso a Lenin, refere-se à necessidade de se apreender as "relações horizontais" que "nos dão a estrutura interna" de uma "sociedade", bem como as "relações verticais", que nos indicam as relações de uma sociedade com as outras sociedades" e nos convidam "a admitir que a evolução de um país interessa não apenas a ele próprio mas igualmente aos outros" (SANTOS, 2008, p. 245). É uma passagem presente também em Gramsci (1975, pp. 1584-5), e que permite ao geógrafo brasileiro, já consciente da crítica que nos anos 70 estabeleceu Pierre Herzog (1973, pp.197-8) a Emilio Sereni - por este operar com a categoria de formação econômico-social dando pouca atenção ao processo de internacionalização do modo de produção capitalista e sua dimensão imperialista -, lançar as bases da categoria de formação econômica social e espacial - e assim da espacialização da gramática de Marx. Como se depreende do raciocínio de Lenin, não se trata da ênfase em uma ou outra escala geográfica específica, mas da apreensão da dialética que aqui se estabelece, também ela uma dialética das "escansões temporais" do espaço (BURGIO, 2003, p. 63). A rigor, um dos momentos da luta de classes, ou ainda uma entre as tantas species - a econômica, a geopolítica, etc - de um mesmo genus, como definiu recentemente Domenico Losurdo, insistindo ser a teoria de Marx uma "teoria geral do conflito social" (LOSURDO, 2013, p. 53).

A história da China não poderia ser um exemplo melhor de observação desta dialética entre o "interno" e o "externo". "Orgulhosa de uma civilização que é uma das mais antigas do mundo", foi "durante um século uma das maiores vítimas do imperialismo, primeiro dos ingleses, depois de outros europeus, dos americanos e por fim dos japoneses", observou o geógrafo Jean Tricart (TRICART, 1990, p. 93). Eis o que compreendeu já Deng Xiaoping ao propor o processo de reformas em 1978, notando que, para "realizar as quatro modernizações", a China tem 
necessidade de construir "um ambiente externo pacífico" (XIAOPING Apud BERTOZZI, 2015, p. 53).

Não se trata de uma dialética restrita às relações entre o capitalismo e o socialismo. A virada em direção à economia militarizada dos anos 60 extraia seus impulsos da crise nas relações com a URSS, que por sua vez tinha como determinação o desejo soviético de degelar as relações com os EUA para aliviar o peso da Guerra Fria e da corrida armamentista (LOSURDO, 2004, p. 147). Esta crise se desenvolveu em três fases: 1) o conflito aberto no ano de 1954 com Taiwan em torno das ilhas Quemoy e Matsu, legitimamente chinesas nas palavras que Churchill envia a Eisenhower (fevereiro de 1955), e diante do qual a URSS se limitava a dar uma cobertura à China que não ia além do seu território continental, com o agravante de Taiwan apresentar-se como clara cabeça-de-ponte de uma invasão da China pelo exército de Chiang Kai-Shek, armado pelos EUA; 2) uma proposta de Kruschov para "formar uma força naval conjunta sino-soviética, que de fato privaria a China de uma força naval autônoma"; 3) o apoio prático dado por Kruschov à India que se recusava a "negociar de forma pacífica um acordo de fronteira" com o grande país asiático, "acreditando poder impor sua vontade com a força das armas" (LOSURDO, 2004, p. 146-7).

No front ocidental também o capitalismo cobrava a sua conta, já que a tragédia iniciada com a Guerra do Ópio ainda se fazia sentir nas pressões estadunidenses, como nos lembra W. W. Rostov, colaborador de Kennedy que se vangloriava de ter conseguido retardar o desenvolvimento da China por dez anos (LOSURDO, 2017, p. 152), mas também a plataforma do candidato republicano (Barry Goldwater) após o assassinato de Kennedy, que falava "como um fascista" e "colocou a guerra em seu programa" (TOGLIATTI, 1980, p. 227). A rigor, trata-se do prolongamento das diretivas da administração Truman (1945-53), ainda em operação à época do Grande Salto à Frente e a preconizar que, estando em "condições desesperadas por decênios de guerras e guerra civil”, a República Popular Chinesa, uma vez "não admitida na ONU", assim como "cercada e ameaçada no plano militar, deveria ser submetida a uma guerra econômica" capaz de "conduzi-la a uma situação econômica catastrófica', 'ao desastre' e ao 'colapso'” (LOSURDO, 2017, p. 152).

Promovida por meio da expulsão dos técnicos soviéticos, bem como através das caluniosas acusações de "aburguesamento" ao país saído da Revolução de 
Outubro (TOGLIATTI, 1980, p. 233) ${ }^{5}$, a militarização da economia então encetada logo foi posta em revisão, processo que tem início já pelo front externo. De fato, é o próprio Mao Zedong que inicia a crítica à Revolução Cultural em 1974, como já havia feito com os primeiros sinais de malogro do Grande Salto à Frente em 1962 (XIAOPING, 1984, p. 372), e é nesse contexto que se deve compreender, já a partir dos primeiros anos da década de 1970, a "normalização das relações com os EUA, o ingresso na Organização das Nações Unidas e o restabelecimento das relações diplomáticas com o Japão" (BERTOZZI, 2015, p. 53).

É precisamente deste período a teorização em torno das "zonas intermediárias", que depois se desdobra na teoria dos "três mundos", base dos princípios da "multipolaridade" nas relações internacionais que agora ocupa o centro da política externa chinesa, fundada no peaceful development. Aliás, já este conceito remete ao início da década de 1950 quando, a propósito das "relações bilaterais acerca da região do Tibet", o primeiro ministro Zhou Enlai propôs à delegação indiana Os Cinco Princípios da Coexistência Pacífica, fundados no "respeito mútuo à soberania e à integridade territorial, não agressão mútua, não interferência nos assuntos internos um do outro, igualdade e benefício recíproco e coexistência pacífica" (JINPING, 2019, p. 37).

Certamente, o processo se desenvolve por fases, observando, como ainda hoje, a "busca da verdade nos fatos", vale dizer, "dos fenômenos tais quais existem objetivamente", lidos por seus "laços internos" (JINPING, 2019, p. 30) - objetividade que é ela mesma a expressão não da simples liquidação das velhas formulações, mas dos laços entre continuidade e descontinuidade que o próprio processo histórico vai tecendo ${ }^{6}$. Assim é que em um primeiro momento, a ideia de "zona intermediária" serve a demarcar as devidas diferenças em relação aos EUA. Já em 1963 Mao Zedong, detendo-se sobre uma série de propostas para uma "linha geral do movimento comunista internacional", estabelece uma clara distinção entre "os imperialistas americanos" e a "zona intermediária" situada entre este mesmo imperialismo e o "campo socialista", incluindo-se nesta "os países capitalistas avançados da Europa ocidental" e o "Japão" - uma zona geográfica para a qual o

\footnotetext{
5 Togliatti aponta, todavia, que a resposta soviética ao conflito com os chineses foi em geral "ideológica e propagandística", quando deveria se ater aos "fatos", à "linha concreta", bem como, segundo procedeu o $\mathrm{PCl}$, através da promoção de "amplas discussões nas assembléias de célula e de seção e nos ativos por cidade." (TOGLIATTI, 1980, pp. 226-7).

"Vale notar como esta definição de "fatos" nada tem a ver com o vulgar empirismo da historiografia positivista. Com efeito, a noção mesma de "laço interno" e de "objetividade" com o qual os "fatos" são apreendidos, faz pensar na realidade em "sentido forte" (Wirklichkeit) que emerge do pensamento hegeliano.
} 
"objetivo estratégico" da potência norte-americana "sempre foi aquele de invadir e dominar", tanto quanto o de "sufocar a revolução dos povos e das nações oprimidas e de destruição dos países socialistas" (LOSURDO, 2019, pp. 25-26). Na década de 1970, quando esta abordagem irá desdobrar-se na teoria dos três mundos, a aproximação com os EUA não irá mudar o que há de essencial - o que constitui a realidade em sentido forte -, como nos permite ver o documento que Zhou Enlai irá relatar na IV Assembléia Popular Nacional, realizada em 13 de janeiro de 1975, insistindo no apoio à "luta dos países e dos povos do segundo mundo contra o controle, as ameaças e os maus tratos das superpotências" (LOSURDO, 2019, p. 27). Base de uma "teoria menos ideológica e mais flexível", a formulação, embora um tanto exagerada quanto à leitura do papel que então cumpria a URSS, fora na verdade já explicitada por Deng Xiaoping no ano de 1974, e assim se apresentava do ponto de vista geoestratégico:

ao lado de um primeiro mundo composto pelas duas superpotências, EUA e URSS (com projetos hegemônicos e em luta para explorar os países mais pobres), se encontra um segundo constituído por forças intermediárias representadas por países industrializados (Japão, Europa, Canadá, Austrália) e um terceiro composto por aqueles menos desenvolvidos e não alinhados: a aliança entre 0 segundo e 0 terceiro permitiria garantir 0 sucesso da luta contra o hegemonismo, objetivo principal da direção chinesa e uma ordem internacional mais pacífica (BERTOZZI, 2015, pp. 5354).

E eis o ponto a partir do qual Deng Xiaoping irá elaborar um "novo caminho diplomático", adaptado aos tempos de "reforma e abertura" - a diplomacia do peaceful development. Ela se funda, é verdade, no abandono da "veleidade e retórica da exportação da revolução" - organizada em torno da ideia do "cerco da cidade pelo campo" -, mas mantém como "princípio cardeal à solidariedade com os países do terceiro mundo e em vias de desenvolvimento", e recolhe como objetivo central "assegurar um ambiente internacional favorável à sustentação do processo de modernização" (BERTOZZI, 2015, p. 53). Os resultados logo aparecerão, como no "acordo sino-britânico de 1984 sobre o retorno à mãe-pátria de Hong Kong" e “aquele sucessivo com Portugal por Macao", resumidos na fórmula "Um país dois sistemas", por sua vez entendida como "exemplo universal para a estabilização pacífica da situação internacional" e como "como solução indispensável para garantir à China aqueles 'vinte anos de paz' úteis para se concentrar no próprio desenvolvimento interno" (BERTOZZI, 2015, p. 54).

O fim da Guerra Fria irá trazer, porém, novas mudanças nos "fatos objetivos", e assim também a diplomacia chinesa irá mudar, mas sem que isso signifique a 
alteração das suas linhas de fundo. É o momento em que os EUA, se apresentando como a "superpotência única e sem rivais", relançam as agressões imperialistas - ou o "novo imperialismo" - por meio de uma aberta adesão ao "unilateralismo", como advertiu o ex-chanceler alemão Helmut Schmidt (LOSURDO, 2019, pp. 126-7). As origens desta redefinição remontam, todavia, ao período Reagan, que "bombardeou Granada" em dezembro de 1983, continuando na administração Clinton, que "bombardeou uma fábrica no Sudão" em 1998 e a "embaixada chinesa em Belgrado" no ano de 1999 - "tudo sem uma resolução do conselho de Segurança da ONU, e tudo em violação da Carta das Nações Unidas" (LOSURDO, 2019, pp. 105-6 e 127). É este o contexto em que, já em 1985, são reativados os "contatos para uma reaproximação com a URSS e um resfriamento nas relações com os EUA", bem como o "progressivo ingresso da China nas principais organizações internacionais", "sobretudo econômicas e financeiras" (FMl e Banco Mundial em 1980), o que contribui para "dar ao país a imagem de uma potência reformadora" "no âmbito do sistema internacional" e confirmar a "tendência progressiva ao multipolarismo" (BERTOZZI, 2015, pp. 54 e 67).

De um ponto de vista das formulações teóricas e seus prolongamentos políticos, este multipolarismo se desdobra na fórmula da Ascensão Pacífica, meio de aplacar, no início do século XXI, os "temores, sobretudo no Sudeste asiático, do crescimento de Pequim", o que corresponde a uma "imagem" de "ator responsável" no sistema internacional, que "não busca nem predomínio, nem hegemonia, mas aponta para uma reforma 'democrática'" deste mesmo sistema, e isto "tanto do ponto de vista político como econômico", de modo a forjar um mundo fundado "no respeito à soberania estatal" e na "escolha autônoma da via de desenvolvimento" (BERTOZZI, 2015, p. 68). É desta formulação, bem como das iniciativas do Cinturão e da Nova Rota da Seda (Belt and Road Initiative), que emerge ainda a teoria da "convergência de interesses", um "modelo de vantagem recíproca e de win-win" (ganha-ganha) (JINPING, Apud BERTOZZI, 2015, pp. 68-9), oposto à "antiquada" "mentalidade do jogo de soma zero" e assim base da "comunidade de futuro compartilhado" (JINPING, 2019, pp. 302 e 360). Para esta democracia internacional, Pequim oferece a "cooperação internacional muldimensional e em múltiplos níveis" (JINPING, 2019, p. 377), retendo fundamental ao "nível global o conceito de 'redes multidimencionais"' - capazes de "alimentar relações de consenso e comunidade de destino entre as diversas potências" -, e assim se dirige a um "reforço de suas 
redes, com particular referência àquelas que não vêem a participação dos EUA: BRICs, Shangai Cooperation Organization e Asean" (BERTOZZI, 2015, p. 69).

Zonas intermediárias, teoria dos três mundos, multipolaridade, ascensão pacífica, redes multidimensionais e comunidade de destino comum, noções tão amarradas umas às outras que é difícil não pensar na consciência de uma gramática que tenha diante de si muito firme a convicção de um "desenvolvimento unitário da história". E justamente porque não comporta a ideia de "exportação da revolução", trata-se de uma convicção aberta a uma "filologia vivente", vale dizer, a uma "coparticipação ativa e consciente" (GRAMSCI, 1975, p. 1430).

\section{Imperialismo e totalitarismo chinês ou alinhamento da esquerda ocidental à ideologia dominante?}

Traçando um quadro dos cenários possíveis na geopolítica contemporânea, o ex-general italiano Carlo Jean crê ser o "mais realístico" aquele que diz respeito a "uma estreita colaboração entre a China e os EUA em uma espécie de 'duopólio imperial'” (JEAN, 2012, p. 246). Não obstante esta virtual semelhança, no plano interno os EUA seriam "uma democracia" onde "o consenso da opinião pública joga um papel essencial", ao passo que a China seria um "regime autoritário e centralizador", e de uma centralização que remete à "China Imperial", à sua "civilização hidráulica com tendência a centralizar o poder" (JEAN, 2012, p. 247 e 256). Isto posto, se poderia concluir que o "apelo ao multipolarismo ao nível global" é "um simples mascaramento dos objetivos de hegemonia" por parte do país asiático, pois "aceitar compromissos" "é inaceitável para toda a cultura político-institucional chinesa, como de outro lado o é para aquela americana" (JEAN, 2012, pp. 250).

Como se pode concluir, não estamos diante do cancelamento da categoria de imperialismo, como Domenico Losurdo acusou em Hardt e Negri, que operando uma "transfiguração das guerras coloniais em operações de polícia internacional", justificaram em 1999 a "guerra contra a lugoslávia" (LOSURDO, 2019, p. 99). Nem por isso, todavia, deixa o ex-general italiano de incorporar a tese do "intervencionismo democrático", "motivo ideológico" que "agora tornou-se um monopólio dos Estados Unidos", apresentado por "politólogos e ideólogos" como "uma espécie de império romano renascido de dimensões planetárias", a defender o "Ocidente" e a "civilização enquanto tal", tanto quanto o fazia a Alemanha hitleriana, que ao seu tempo também se apresentava como "a campeã da supremacia ou da missão ocidental, branca e ariana" (LOSURDO, 2019, pp. 114-116). De fato, não é 
outra senão esta a conclusão a extrair de uma avaliação geopolítica que, em referência à onda de vitórias dos governos de esquerda, conclui estar a América do Sul se "afastando culturalmente do Ocidente e assumindo características originais", na medida em que o "centro do poder político e econômico se está deslocando das zonas temperadas e europeizadas do Cone Sul" para a "bacia do Rio Amazonas e o Brasil" (JEAN, 2012, p. 277). Num e noutro caso, nada da gramática de Marx, mas uma geopolítica do "essencialismo dos povos", para usarmos uma expressão cara à crítica que, curiosamente, endereça o filósofo italiano aos deslizes do "marxismo ocidental" (LOSURDO, 2017, p. 103).

E eis um ponto central. A tese do imperialismo e da sociedade autoritária para a caracterização da formação social chinesa, aparecendo, na geopolítica de traços conservadores que aqui fizemos notar, sob a forma da emulação de uma antropologia médica de triste memória - a antropologia lombrosiana (GRAMSCI, 1975, p. 2279) -, se encontra, embora nem sempre operando a mesma emulação, fartamente distribuída na esquerda ocidental quando esta se põe diante da China. $E$, com efeito, se nem sempre é o "lombrosiano" "essencialismo dos povos" que está presente, a ausência da questão colonial é a nota dominante.

A análise do geógrafo David Harvey (2012) não vai tão longe, é verdade. Nela não há concessões ao essencialismo dos povos e até se descreve "corretamente" determinadas situações - e. g. caracteriza as mudanças de 1979 como uma tentativa da China de "desenvolver as capacidades tecnológicas" e "defender-se melhor contra as agressões externas" (LOSURDO, 2017, pp. 154-5) -, mas em si não é menos falha. Segundo Losurdo, Harvey não dá conta da "revolução anticolonialista", e isto "tanto no que diz respeito ao presente quanto no que se refere ao passado" - no último caso ignorando a "guerra de resistência do povo chinês contra a agressão do imperialismo japonês", ao passo que, descrevendo corretamente o motivo das reformas de 1979, termina por reduzir sua análise à tese da rivalidade interimperialista, afirmando que "na passagem do século $X X$ ao $X X I$ 'começam a se fazer sentir os ecos da competição geopolítica que se tornou destrutiva nos anos 30" e produziu "as crises do capitalismo global nas décadas de 1930 e 1940" (HARVEY, 2012, pp. 64 e 167; LOSURDO, 2017, pp. 153 e 155). Certamente, não estamos diante das tintas kautiskyanas, centradas na "união dos imperialismos", que aparece na geopolítica conservadora antes citada. Não obstante, refém de uma noção de história que parece ser apenas aquela da nietzschiana "repetição do idêntico" (LOSURDO, 2017, p. 155), o geógrafo britânico 
se inclina para a tese das rivalidades que "constituem a própria essência" do imperialismo da época de Lenin (LÉNINE, 1981a, pp. 643-5). Num e noutro caso, permanece a aplicação da categoria de imperialismo à China.

Em Slavoj Žižek (2011), porém, o espectro da geopolítica conservadora parece inteiramente presente. Continuemos com a crítica de Losurdo. A "remoção da questão colonial é parte integrante da plataforma teórica e política do filósofo esloveno" (LOSURDO, 2017, p. 146-8). Seu argumento, "não menos hostil que Hanna Arendt à categoria de Terceiro Mundo", aliás "até mais radical", afirma que o mundo "é dominado de modo integral pelo capitalismo" e "não há sentido distinguir as potências imperialistas e colonialistas dos países que há pouco se libertaram do domínio colonial" e tentam "a plena independência também no plano econômico", buscando para isto elaborar "instituições políticas adequadas às suas condições econômico-sociais e às suas situações geopolíticas" (LOSURDO, 2017, p. 148). E eis que, "esvaziado o terreno das categorias de Terceiro Mundo, imperialismo, antiimperialismo", a "única distinção sensata seria aquela entre "capitalismo autoritário' e não", a primeira das categorias a ser aplicada "em primeiro lugar à China", mas "podendo ser inseridos também o Vietnã" e talvez até "Cuba, após a recente abertura ao mercado e à economia privada", tanto quanto "os países da 'América Latina' marcados por um 'capitalismo populista', propensos ao caudilhismo e ao autoritarismo" (ŽlŽEK, 2011, p. 361; LOSURDO, 2017, p. 148). Não há dúvida, estamos diante daquele "essencialismo dos povos" que, já ao tempo do deslizamento chauvinista da II internacional, marcou até mesmo autores como Kautsky, que se referindo à Revolução de Outubro, "remetia mais à "essência oriental' do que à história e à geografia" - isto é, à geopolítica -, mas não menos, muitos anos depois, também um representante de estatura da Escola de Frankfurt como Horkheimer, que pretendia explicar “Stalin e Mao e o 'aparato totalitário' por eles posto em prática com 'a crueldade coletiva praticada no Oriente"' (LOSURDO, 2017, pp. 103-4).

O que acabamos de expor foi um quadro ideológico que teima em se repetir no Ocidente quando o assunto é a China e mais geralmente os países com história colonial, chegando mesmo a aproximar direita e esquerda. E, de fato, do ponto de vista desta última, trata-se de "um claro alinhamento à ideologia dominante" (LOSURDO, 2017, p. 137), vale dizer, à ideologia emanada da superpotência norteamericana, pois "sob o plano ideológico as relações de força estão desequilibradas 
em favor dos Estados Unidos de modo ainda mais claro do que sob o plano militar" (LOSURDO, 2019, 116).

\section{A pandemia e ainda o peso da questão ideológica}

Não deve haver dúvida de que a pandemia da Covid-19 provocou na superpotência estadunidense uma redobrada agressão política e ideológica contra a China. Para ter certeza disto basta percorrer os grandes jornais da mídia corporativa, onde se pode ler notícias como a de que "os senadores republicanos candidatos à reeleição foram instruídos pelo comando do partido a 'atacar a China'”, utilizando-se, compreende-se, a retórica do "vírus chinês" (SÁ, 2020, p. A13).

Não obstante, esta não é uma operação que se iniciou com a pandemia, remetendo antes às formas pelas quais os Estados Unidos estão lidando com a emergência da China no cenário internacional. Vejamos a tese do "imperialismo chinês". Se o Itamaraty do governo Bolsonaro agora organiza seminários para debater teses que falam de um "plano" "implementado por Xi Jinping" com a "ajuda da ONU" para "o domínio chinês no hemisfério Sul" e para "colonizar outros países" (ONOFRE, 2020, p. A18), já em 2018, na Cúpula da Apec-Asia-Pacific Economic Cooperation, quando precisamente se discutia a Belt and Road Initiative, o vicepresidente Mike Pence referia-se ao grande país asiático como um "neoimperialismo", dados os investimentos que este mantinha nos países pobres, supostamente gravosos do ponto de vista econômico (CARRER, 2019). Do mesmo modo, se agora os EUA se lançam em uma estratégia de fortes ataques à ONU e ao sistema multilateral, em especial às "organizações mundiais da saúde, do comércio e do trabalho" (CHADE, 2019), é preciso recordar que o unilateralismo que caracteriza a redefinição da ordem imperialista, completamente dominada pelos EUA, remete já à era Reagan.

Igual advertência deve ser feita no que diz respeito à tese do "totalitarismo chinês". Não passa despercebido ao leitor mais atento que a administração Trump se prepara para usar contra a China a retórica utilizada contra o talibã, vale dizer, definindo-a, num claro recurso ao "essencialismo dos povos" que embala a teoria do totalitarismo, como país terrorista ou mesmo fascista. "Passamos pelo pior ataque que já tivemos em nosso país... É pior do que Pear Harbor. É pior que o do World Trade Center", declarou Trump referindo-se à propagação da Covid-19 nos EUA (POLITI, 2020, p. A-9). Também esta, todavia, não é uma retórica nova, pois já em 2001, sob a administração Bush, a imprensa europeia alertava que Jiang Zemin 
deveria ter em conta que "'a batalha contra os talibãs é conduzida em nome de princípios que poderiam ser aplicados um dia' contra a própria China (mais do que contra a Rússia)" (LOSURDO, 2019, p. 95).

De fato, não é outro senão o contexto ideológico onde estão inseridas as formulações do marxismo ocidental que antes vimos, sempre muito arredias à história e à geografia do colonialismo. Cabe averiguar mais de perto estes argumentos, recorrendo a dados históricos, ao rigor filológico dos conceitos e às evidências estatísticas.

Uma pesquisa conduzida por Deborah Brautigam, da Johns Hopkins School of Advanced International Studies, indagando-se acerca de uma tese muito difundida no noticiário ocidental, a saber, a tese do colonialismo chinês na África, supostamente organizado para suprir as necessidades de alimentos do país asiático, concluiu que a "China detém menos de $1 \%$ de todas as terras aráveis do continente" (BRAUTIGAM, 2015, p. 152). E embora a agricultura, desde as políticas de 'expansão global' de 2001, esteja entre as atividades apoiadas pelo governo chinês, o China Eximbank exclui o financiamento de aquisição de terras no exterior, tendo concentrado seus recursos, ao lado do China Development Bank, não tanto para financiar suas próprias companhias agroindustriais, mas antes os governos africanos em projetos como fazendas estatais (Angola), fábricas de processamentos de produtos agrícolas (Moçambique), refinarias de açúcar (Etiópia) - e isto através de um padrão de negócios que não tem por objetivo a reexportação de alimentos para a China (BRAUTIGAM, 2015, pp.155-6). De fato, segundo dados da ONU, entre 2004 e 2014, a China não importou produtos básicos de sua dieta da África, como trigo e arroz, e apenas pequenas quantidades de milho, mandioca e soja entraram na China procedentes da África neste período (BRAUTIGAM, 2015, p. 156). São conclusões decisivas, ainda mais se pensamos que elas são diretamente confrontadas com dados fornecidos pelo jornalista do New York Times e professor da Columbia University, Howard French, que sustentando a tese da construção de um império chinês na África, com aquisições de terras e até mesmo transferência de população, falou de uma aplicação de US\$ 5 bilhões em projetos agrícolas por parte do China Africa Development Fund (CAD-Fund) - os valores não passaram de US\$ 57 milhões (BRAUTIGAM, 2015, p. 155).

Podemos nos perguntar se os investimentos chineses na África não dizem respeito ao padrão das "exportações de capital", quando a fusão banco-indústria no pólo imperialista implica que nas "cláusulas do empréstimo se imponha o gasto de 
uma parte do mesmo na compra de produtos ao país credor" (LÉNINE, 1981ª, p. 624). É preciso notar, porém, que a definição de Lenin comporta uma crítica ao esquecimento de Kautisky quanto ao fato de que o que "é característico do imperialismo não é precisamente o capital industrial, mas o capital financeiro", e que "precisamente o desenvolvimento particularmente rápido do capital financeiro", coincidindo com "um enfraquecimento do capital industrial", leva a "uma intensificação extrema da política anexionista (colonial)", como ocorreu na França da década de 80 do século XIX (LÉNINE, 1981a, p. 643). Nada na China lembra esta dinâmica. Já vimos não se confirmarem as notícias acerca de uma forma qualquer de anexionismo por parte da China na África, e até mesmo em razão do predomínio do planejamento, ao capital financeiro é reservada uma posição subordinada na dinâmica econômica do "socialismo de mercado". De fato, não por outro motivo, cada vez mais esta dinâmica se orienta ao mercado interno, que respondeu em 2019 por cerca de 2/3 do PIB do país (POMAR, 2020). São já os efeitos da construção do Welfare chinês, não há dúvida, que todavia tem ainda um logo caminho pela frente, pois a divisão do já agigantado PIB pela população total mostra que a China é ainda refém de uma "base econômica fraca" e de um "desenvolvimento desequilibrado": em 2013 este critério colocava o país na 90a posição no ranking mundial (JINPING, 2019, p. 371).

Uma indagação poderia ser feita ainda quanto à iniciativa do Cinturão e Rota da Seda, com a qual a China projeta sua inserção internacional. O padrão de acumulação e de relações internacionais que emerge desta iniciativa, nada tem a ver com o imperialismo nas características acima descritas. Vejamos as declarações que emergem do Fórum de Cooperação China-Países Árabes, os últimos, como se sabe, objeto de seguidas agressões do eixo imperialista EUA-Israel. O "espírito" da iniciativa chinesa, afirma-se, é o de "conectar seu próprio desenvolvimento com o desenvolvimento dos países árabes, apoiando-os na oferta de empregos, na industrialização e no desenvolvimento econômico", ou seja, o do "fortalecimento das forças endógenas do crescimento econômico" (JINPING, 2019, pp. 378-9), algo impossível de se realizar pelos mecanismos de exportação de capitais descritos por Lenin, por definição desindustrializantes, se não pelo caminho estritamente econômico, por aquele das anexações coloniais. Quiçá ainda preso à exigência das evidências estatísticas, quisesse um critico insistir no caráter apenas retórico da referência que acabamos de apresentar, posto tratar-se do discurso de um chefe de Estado. Mas uma tal crítica apenas estaria dando prova de sua negligência frente à 
"história e à geografia" do colonialismo: a China, já em 1955, na Conferência de Bandung (Indonésia), assumiu "perante os países árabes" o "compromisso" de "apoiar a luta do povo palestino", e continua a fazê-lo, posto que "apoia firmemente o processo de paz no Oriente Médio e apoia a criação do Estado da Palestina com plena soberania, tendo Jerusalém Leste como Capital e com base nas fronteiras demarcadas em 1967" (JINPING, 2019, pp. 376-8).

$\mathrm{E}$ ainda assim, se precisássemos recorrer às estatísticas, elas são eloqüentes. Em 2016, do total de empresas européias detidas por indivíduos ou empresas estrangeiras, $29 \%$ delas era de propriedade estadunidense e apenas $9 \%$ de propriedade chinesa, sendo a vantagem norte-americana ainda maior em termos do controle do valor dos ativos, detendo $62 \%$ - o maior entre os controladores estrangeiros - contra apenas 3\% dos chineses (PENA, 2019). E, ainda mais em consonância com o espírito da Belt and Road Initiative e em franca oposição aos padrões de acumulação do imperialismo de que falou Lenin, os investimentos chineses se diferenciam claramente daqueles que partem dos Estados Unidos, já há algum tempo sob controle dos chamados investidores institucionais e assim dominados pelas finanças (CHANDLER, 1990, pp. 594-5). É o chefe de uma fabricante de máquinas européias com sede em Munique (Krauss Mafei) adquirida por uma empresa chinesa quem o diz, afirmando que após a transferência de patrimônio, sua empresa passou a investir "duas vezes mais por ano do que nos anos sob a liderança dos investidores institucionais", tendo sido já criados "800 novos postos de trabalho" (PENA, 2019).

Resta tratar da tese do totalitarismo. Não é surpresa que um autor como Karl Popper, já definido o "teórico oficial" da "sociedade aberta", afirme a coincidência entre "fascismo e comunismo", e até mesmo afirme "de modo explícito o caráter benéfico da recolonização" que se abre com a queda da URSS e a guerra contra o Iraque (LOSURDO, 2013, p. 55; LOSURDO, 2019, p. 79). Mas tão-pouco é surpresa se, observando a negligência diante do método de Marx, flagramos também representantes do pensamento marxista sustentando o mesmo ponto de vista. Com efeito, já na esteira da política de reforma e abertura, Deng Xiaoping insiste que aquele é também o contexto em que se deveria "implantar efetivamente o sistema democrático e a legalidade socialistas" (XIAOPING, 1984, p. 375), hoje apontados, em relação à Constituição Provisória de 1949 e à Constituição da República Popular de 1954, como um "aperfeiçoamento do sistema legal socialista", empenhado, sim, na "construção de um Estado de direito socialista" (JINPING, 2019, pp. 166-7), mas 
sem que isso signifique copiar "mecanicamente o sistema político ocidental" (JINTAO Apud BERTOZZI, 2015, p. 64). De qualquer modo, sob clara inspiração do Prefácio de Marx, compreende-se que a reforma em "áreas cruciais" e o "aceleramento da transformação do modelo econômico" articulam "exigências" que se referem "tanto às forças produtivas e às relações de produção quanto à base econômica e à superestrutura" (JINPING, 2019, pp. 15-16).

De fato, o "sistema do Estado" continua a ser definido como uma "ditadura democrática popular sob liderança da classe operária com base na aliança dos operários e camponeses" - vimos anteriormente que também os "intelectuais" são parte desta "espinha dorsal" -, tendo por base um "sistema político" apoiado "nas assembléias populares", mas também "um sistema de cooperação multipartidária e de consulta pública sob liderança do PCCh", e ainda um "sistema de autonomia regional étnica" e outro de "administração das massas a nível de base" - tudo a incluir a "Frente Única patriótica", o "centralismo democrático" e a "salvaguarda dos direitos humanos" (JINPING, 2019, pp. 169-70). Este último, é preciso notar, apresentando-se sob a forma socialista e marxista, vai muito além da concepção liberal ocidental. Enquanto "a visão ocidental dos direitos humanos é referida ao indivíduo particular", e assim "se limita aos também muito importantes direitos civis e liberdade pessoais", a China socialista tem destes direitos uma ideia "muito mais ampla", referindo-se "à pessoa na sua relação com os outros, ao indivíduo em relação à sociedade, em suma ao homem como ser social", envolvendo "a saída da pobreza, a emancipação das necessidades e portanto um desenvolvimento mais equânime no plano mundial", "pressuposto fundamental para a construção de uma comunidade humana realmente unitária" (PUNCOG, 2018, pp. 269-70). E eis que toda esta nova concepção de direito, bem como o arranjo institucional que lhe acompanha, não teme dialogar e introduzir - tal como fora feito com a tecnologia e a economia de modo mais geral - as formas mais avançadas que o Ocidente alcançou. De fato, toda a "virada legalista" levada a efeito na Constituição de 1982, se caracteriza precisamente por uma maior "divisão das tarefas, poderes e funções", com o PCCh assumindo a "tarefa de direção do trabalho ideológico e político", que "não deve se identificar com o trabalho administrativo dos órgãos de governo nem com a direção da produção das empresas ou substituir-se a elas", bem como por princípios como o da "igualdade dos cidadãos diante da lei" - "desaparecido nas constituições posteriores àquela de 1954" -, o que leva ao desaparecimento das chamadas "categorias negras" - os "ex-proprietários de terra", os "capitalistas 
burocráticos" e "contrarrevolucionários vários" -, anteriormente "excluídas do gozo dos direitos políticos" (BERTOZZI, 2015, p. 56).

\section{À guisa de conclusão}

A tese que põe em questão o socialismo de mercado chinês não encontra base de sustentação seja nas formulações teóricas dos grandes revolucionários da história do socialismo, seja na própria teorização dos revolucionários chineses. Do mesmo modo, tomando-se os contextos históricos e geográficos, bem como as estatísticas, é pouco crível afirmar que a projeção internacional deste socialismo de mercado tenha tomado a forma do colonialismo ou do imperialismo. Trata-se, antes, de "coparticipação ativa e consciente" (GRAMSCI, 1975, 1430)

Certamente, deixando para trás as estatísticas e o processo históricogeográfico, poderíamos insistir que o "novo imperialismo", diferentemente daquele que emerge no final do século XIX, se sustenta antes na "retórica" e na "propaganda", vale dizer, no terreno das ideologias (ALI e BARSAMIAN, 2005, p. 35). Ora, como antes vimos, este é justamente o terreno em que "as relações de força estão desequilibradas em favor dos Estados Unidos” (LOSURDO, 2019, 116), não havendo sentido tomá-lo como critério para ler a internacionalização chinesa.

Quanto à forma do Estado, lida como totalitária nos círculos políticos e intelectuais do Ocidente, se tomamos como critério de definição da categoria de totalitarismo aquele da Escola de Frankfurt, que com Horkheimer fala da "crueldade coletiva praticada no Oriente", ou ainda o muito utilizado critério da última Arendt, que "em chave psicológica e psicopatológica" a lê como o "desprezo totalitário pela realidade e a factualidade" (LOSURDO, 2017, pp. 104 e 115), de modo algum podemos utilizá-la - ou mesmo aquela de autoritarismo, tão apegada ao "essencialismo dos povos" como esta - para falar do socialismo chinês. Trata-se de uma experiência já distante da ideia de um "passado" e dos "sistemas filosóficos passados" como algo apenas "'irracional' e 'monstruoso"', um mero "tratado" de "teratologia" (GRAMSCI, 1975, p. 1417), e assim aberta a um processo de "aprendizagem" que inclui a incorporação, sempre dialética, das mais elevadas conquistas da civilização mundial (LOSURDO, 2004, pp. 99 e segs.). Se, como define Guido Liguori, na "leitura fortemente inovativa" - "mas nunca em contraste explícito" com aquela de Marx e Engels - da concepção de ideologia do jovem Gramsci, depois retomada nos Cadernos do Cárcere, encontramos duas semânticas do termo, verbi gratea, como algo "risível", "pura tagarelice destinada a criar 
confusão, a iludir e submeter energias sociais potencialmente antagonistas", e como "entidades históricas potenciais, em formação" (LIGUORI, 2009, p. 400), é forçoso concluir que ao Ocidente cabe o primeiro sentido, a toda prova uma forma deteriorada, enquanto à China cabe o segundo sentido. A diferença central, segundo acenamos já no início deste artigo, termina por ser a concepção "unitária da história", cara à filosofia clássica alemã da qual o materialismo histórico é herdeiro herança já totalmente esmaecida no marxismo ocidental ou mesmo, quando inteiramente subordinado à forma mentis pós-moderna, completamente abandonada.

\section{Referências}

ALI, Tariq e BARSAMIAN, David. Imperialismo: antes e agora. In: Imperialismo e resistência. São Paulo: Expressão Popular, 2005.

AZZARÀ, Stefano G. Nonostante Laclau. Populismo ed egemonia nella crisi della democracia moderna. Mimesis: Milano-Udine, 2017.

BARELLA, José E. A Guerra Fria digital. In: Valor Econômico, 15/05/2020 (Caderno de Fim de Semana)

BERTOZZI, Diego A. La Cina della riforma: un percorso storico-ideologico. In: Marx Ventuno, $n^{\circ} 2-3,2015$.

BODEI, Remo. Introduzione. In: Rosenkranz, K. Vita di Hegel. Bompiani: Milano (It), 2012.

BRAUTIGAM, Deborah. Will Africa feed China? Oxford-New Your: Oxford University Press, 2015.

BURGIO, Alberto. Gramsci storico. Una lettura dei 'Quaderni del carcere'. Roma-Bari, 2003.

CARRER, Stefano. Pechino e i dubbi sulle nuove Vie della Seta. In: Il sole 24 Ore, 24/02/2019.

CHANDLER JR. Alfred. The dynamics of industrial capitalism. In: Scale and Scope. Massachusetts: Harvard University Press, 1990.

CHADE, Jamil. EUA planejam G7 com Brasil e aliados para evitar domínio chinês pós-covid. In:https://noticias.uol.com.br/colunas/jamil-chade/2020/06/04/covid-19-e-duelo-eua-x-chinacomecam-a-redesenhar-mapa-de-forcas-mundiais.htm (Acesso em 4/06/2020)

D'ORSI, Angelo. Gramsci. Una nuova biografia. Milano: Feltrinelli, 2018.

GRAMSCI, Antonio. Alcuni temi della quistione meridionale. Scritti polititici, Roma: L'Unità, 1967.

GRAMSCI, Antonio. Quaderni del Carcere. A cura di Valentino Gerratana. Torino: Einaudi, 1975. 
GRAMSCI, Antonio. Lettere dal carcere - 1926-1937. A cura di Antonio A. Santucci, Palermo: Sallerio editore, 1996.

GREENREPORT. http://www.greenreport.it/news/agricoltura/il-mondo-e-diventato-piu-verdegrazie-a-cina-e-india/ (Acesso em 21.02.2019).

HARVEY, David. O novo imperialismo. 6 ed. Trad. Adail Sobral e Maria S. Gonçalves. São Paulo: Loyola, 2012.

HEGEL, Georg W. F. Enciclopedia delle scienze filosofiche. 2 ed., trad. Benedetto Croce. Roma-Bari: Laterza, 2009.

HERZOG, Pierre. El punto de vista de un economista. In: El concepto de 'formación económico-social'. Siglo XXI, Argentina, 1973.

JABBOUR, Elias. A "Nova Economia do Projetamento" como uma variação de nível superior do socialismo de mercado chinês. In: Grupo de trabajo CLACSO - China e y mapa del poder mundial, $\mathrm{n}^{\circ} 1$, maio de 2020.

JEAN, Carlo. Geopolítica del mondo contemporaneo. Roma-Bari: Laterza, 2012.

JINPING, Xi. A governança da China. Tomo I. Rio de Janeiro: Contraponto; Foreign Language Press, 2019.

LIGUORI, Guido. Ideologia. In: Dizionario gramsciano - 1926-1937. A cura di Guido Liguori e Pasquale Voza. Roma: Carocci, 2009.

LÉNINE, Vladimir I. Imperialismo, fase superior do capitalismo. In: Obras Escolhidas. Tomo 1. Moscou: Progresso; Avante!: Lisboa, 1981․

LÉNINE, Vladimir I. O infantilismo de esquerda e o espírito pequeno-burguês. In: Obras Escolhidas. Tomo 2. Moscou: Progresso; Avante!: Lisboa, 1981 ${ }^{\text {b }}$.

LÉNINE, Vladimir I. Relatório sobre a substituição das requisições pelo imposto em espécie de 15 de março. X Congresso do PCR(b). In: Obras Escolhidas. Tomo 3. Moscou: Progresso; Avante!: Lisboa, 1982.

LOSURDO, Domenico. Fuga da História. A Revolução russa e a revolução chinesa vistas de hoje. Trad. L. M. Gazzaneo e C. M. Saliba. Rio de Janeiro: Revan, 2004.

LOSURDO, Domenico. Hegel e la libertà dei moderni. Napoli: La scula di Pitagora, 2011.

LOSURDO, Domenico. La lotta di classe. Una storia politica e filosofica. Roma-Bari: Laterza, 2013.

LOSURDO, Domenico. Gramsci e la Russia soviética: il materialismo storico e la critica del populismo, in: Materialismo Storico, nº 1-2, 2016.

LOSURDO, Domenico. II marxismo occidentale. Come nacque, come morì, come può rinascere. Roma-Bari: Laterza, 2017.

LOSURDO, Domenico. Imperialismo e questione europea. A cura di Emiliano Alessandroni, Napoli: La Scuola di Pitagora, 2019.

MARX, Karl. Contribuição à Crítica da economia Política. Trad. Ma. H. Barreiros Alves. São Paulo: Martins Fontes, 1983. 
OLIVEIRA, Amaury P. Formação de uma economia regional no leste asiático. In: Cadernos Geográficos, n¹3, 2006.

POLITI, James. EUA estudam medidas mais duras contra a China. In: Valor Econômico de 7/05/2020, P. A-9).

POMAR, Milton. China: 2020. In: https://amanha.com.br/mundo/china-2020-em-seismeses (Acesso em 29/04/2010).

PENA, Paulo. China na Europa, parceiro ou rival? In: https://www1.folha.uol.com.br/mundo/2019/09/china-na-europa-parceiro-ou-rival.shtml (Acesso em 1/10/2019)

PUNCOG, Qiangba. Cina: i diritti umani tra sviluppo sociale e destino comune dell'umanita. In: L'egemonia del socialismo. Governa la Cina difende la pace sviluppa l'Europa. Teramo: Centro Gramsci di Educazione, 2018.

SÁ, Nelson de. China dispara compra de soja dos EUA; câmbio ajuda Brasil. In: Folha de São Paulo, 27/04/2020.

SANTOS, Milton. Por uma geografia nova. São Paulo: Edusp, 2008.

TESETUNG, Mao. Sobre a questão da burguesia nacional e dos nobres esclarecidos. In: Obras Escolhidas de Mao Tsetung. Tomo IV. São Paulo: Alfa Ômega, 1979.

TOGLIATTI, Palmiro. Memorial de Ialta. In: Socialismo e democracia: escritos escolhidos do período 1944-1964. Trad. C. N. Coutinho. Rio de Janeiro: Ilha, 1980.

TRICART, Jean. Nova Política Econômica na China. In: Geosul, nº 10, 1990.

WOOD, Ellen M. A origem do capitalismo. Trad. Vera Ribeiro. Rio de Janeiro: Jorge Zahar, 2001.

XIAOPING, Deng. Respuestas a La periodista italiana Oriana Fallac. In: Textos Escogidos de Deng Xiaoping. Beijing: Edicione em Lenguas Extranjeras, 1984.

ŽlŽEK, Slavoj. Em defesa das causas perdidas. Trad. Maria B. de Medina. São Paulo:

Boitempo, 2011.

\section{NOTAS DE AUTOR}

\section{CONTRIBUIÇÃO DE AUTORIA}

Marcos Aurélio da Silva - Concepção. Coleta de dados, Análise de dados, Elaboração do manuscrito, revisão e aprovação da versão final do trabalho

\section{FINANCIAMENTO}

Não se aplica.

CONSENTIMENTO DE USO DE IMAGEM

Não se aplica.

\section{APROVAÇÃO DE COMITÊ DE ÉTICA EM PESQUISA}

Não se aplica.

CONFLITO DE INTERESSES

Não se aplica.

Este artigo está licenciado sob a Licença Creative Commons CC-BY. Com essa licença você pode compartilhar, 
adaptar, criar para qualquer fim, desde que atribua a autoria da obra.

\section{HISTÓRICO}

Recebido em: 20-08-2020

Aprovado em: 03-10-2020 